Article

\title{
Preliminary Human Safety Assessment (PHSA) for the Improvement of the Behavioral Aspects of Safety Climate in the Construction Industry
}

\author{
Mario Fargnoli * (D) and Mara Lombardi (D) \\ Department of Chemical Engineering Materials Environment (DICMA), Sapienza-University of Rome, \\ via Eudossiana 18, 00184 Rome, Italy; mara.lombardi@uniroma1.it \\ * Correspondence: mario.fargnoli@uniroma1.it
}

Received: 15 February 2019; Accepted: 13 March 2019; Published: 18 March 2019

check for updates

\begin{abstract}
Occupational safety in the construction industry still represents a relevant problem at a global level. In fact, the complexity of working activities in this sector requires a comprehensive approach that goes beyond normative compliance to guarantee safer working conditions. In particular, empirical research on the factors influencing the unsafe behavior of workers needs to be augmented. Thus, the relationship between human factors and safety management issues following a bottom-up approach was investigated. In particular, an easy-to-use procedure that can be used to better address workers' safety needs augmenting the company's safety climate and supporting safety management issues was developed. Such an approach, based on the assessment of human reliability factors, was verified in a real case study concerning the users of concrete mixer trucks. The results showed that the majority of human failures were action and retrieval errors, underlining the importance of theoretical and practical training programs as a means to improve safety behavior. In such a context, information and communication activities also resulted beneficially to augment the company's safety climate. The proposed approach, despite its qualitative nature, allows a clearer understanding of workers' perceptions of hazards and their risk-taking behavior, providing practical cues to monitor and improve the behavioral aspects of safety climate. Hence, these first results can contribute to augmenting safety knowledge in the construction industry, providing a basis for further investigations on the causalities related to human performances, which are considered a key element in the prevention of accidents.
\end{abstract}

Keywords: construction safety; safety climate; safety management; human reliability analysis; human behavior; risk assessment

\section{Introduction}

The construction industry is considered a very risky sector [1], since the rate of accidents is constantly high at a global level [2]. Such a phenomenon also has a significant economic and social impact [3]. The determining factors of this situation can be found in the peculiarities of the construction sector [4]. In fact, the combination of the following aspects, such as frequent employee turnover, subcontracting and stringent contract deadlines, outdoor work in all weather conditions, lack of highly trained workers, use of obsolete working equipment, frequent change of work sites, as well as the presence of different companies on the same site contemporaneously contributes to the high rate of accidents and injuries [5]. Consequently, analysis of accident causality and the definition of the related measures for safety management represent a complex task [6].

In order to deal with such a complexity, Mitropoulos et al. [7] highlighted the need of analyzing the characteristics of working tasks, given that the normative approaches hardly consider the characteristics 
of the working processes in a proper manner. As a matter of fact, the improvement of human safety relies on the reduction of the risks for the workers when performing specific working activities considering human factors [8]. Accordingly, specific work situations should be considered with more attention, since ensuring the safety of the various tasks is the precondition for ensuring a higher level of safety from both a project and an operative perspective [9]. This means that more attention has to be paid to the analysis of human behavior [10], and to the factors that can impact on it, such as stress, training, experience, etc. [11]. In fact, as per Llory [12], a human-centered approach is needed, since "safety is, above all, behavioral and individual". In particular, the analysis of the perception of unsafe conditions and actions plays an important role for the implementation of a safety system in construction projects [13], while the augmentation of safety behavior can directly influence the safety climate and the safety performances of workers [14]. Safety climate can be intended as the workers' perception of the safety management issues implemented by the company [15], and multiple factors contribute to its improvement [16]. Among them, certainly human factors play a consistent role, since, despite the ever-stricter issue of safety regulations and procedures, workers still fail in performing their activities [17]. Consequently, an improvement of safety performances in terms of human factors can positively influence the workers' concerns on safety issues in a working environment [18]. Accordingly, Liao et al. [19], analyzing several construction case studies at the project level, put forward the close relationship between safety climate and human factors. This aspect was also highlighted by Glendon and Stanton [20], who advised safety managers to consider the analysis of human error to better understand human interaction with working tasks, augmenting the safety climate by means of a bottom-up approach. However, although a positive perception of safety allows a safer behavior of workers, and consequently a likely reduction of accidents, further investigation of these relationships is needed to better understand the impact of human factors on safety management and safety behavior issues [21]. In particular, empirical research on the factors influencing unsafe behavior on construction sites needs to be augmented [22].

Following these research clues, our study is focused on the development of an easy-to-use procedure to understand workers' behavior through a bottom-up analysis, which can be used to better address the workers' safety needs augmenting the company's safety climate and supporting safety management issues.

More in detail, the proposed framework is based on the analysis of work activities, integrating information concerning workers' behavior and reliability by means of human error prediction techniques [23] and examining how human interaction with work equipment and other personnel operating at the same site can influence the potential risks.

The remainder of the paper is articulated as follows: the next section discusses the research background. In Section 3, the research approach is depicted and in Section 4 its application in a practical context (i.e., two small-sized companies specialized in the distribution of concrete) is described. Section 5 discusses the results achieved addressing further research work, while Section 6 concludes the paper.

\section{Previous Studies}

Traditionally, human factors are regarded as the analysis of the interactions between man and work equipment, as well as the work environment [24]. The evaluation of human error is a proven way to enhance the performance and reduce the risk of accidents [25]. In literature, several tools addressing this goal, also called Human Reliability Analysis (HRA), can be found [26]. The analysis of human factors has been largely adopted in safety critical industries within sectors such as nuclear plants [27], marine systems [28], railway and aviation industry [29], as well as chemical plants, etc. Conversely, the use of these tools in other work contexts is not common, mainly due to their complexity in terms of both computational efforts and resource involvement [30].

In the construction industry, most studies deal with the analysis of workers' behavior considering an ergonomics perspective [31], especially those focusing on the work equipment characteristics [32]. 
For example, Choudhry [33] reviewed numerous case studies of companies and workers that have successfully applied the behavior-based safety (BBS) approach in casualty prevention. Accordingly, Li et al. [34] proposed an augmented version of the BBS model, which resulted in effectively improving the efficiency of safety management. Behavior-based safety has also been analyzed by means of a system dynamics approach in order to highlight the feedback effects of such a model [35]. Wu et al. [36] developed a stress scale for construction workers, establishing a correlation between the dimensions of job stress and those of safety behavior. Nevertheless, these types of analyses can be time-consuming, as they require a sufficient monitoring period, as well as resource consumption due to the need for specialists for the analysis of results, making their implementation by small-sized companies difficult [23]. Other studies propose the application of visual tools and advanced technology to reduce human errors improving the safety performances $[37,38]$. However, the implementation of the above models in small- and medium-sized enterprises (SMEs) has to be investigated, specifically as their safety needs might differ from those of large-scale companies [39]. Moreover, SMEs' workers showed a lower level of perception of safety knowledge than those from large companies [40], mainly due to the lack of resources and of a structured management organization [41], as well as the fact that often the exchange of tasks causes a low level of specialization [42].

Focusing more on the human reliability analysis, Moaveni et al. [43] proposed the use of lean construction approaches for construction projects since they can reduce the possibility of human errors, improving safety performances. Besides, Ye et al. [44] proposed an improved Human Factors Analysis and Classification System (HFACS) approach to determine key human factors that can lead to an improvement of safety performances. Notwithstanding the relevance of the insights of these works, the assessment and monitoring of the behavior of workers focusing on the human reliability aspects is still scarcely considered in the construction sector [45]. Mostly, they propose top-down approaches that can be used mainly at a project level, while a bottom-up approach should be preferred to provide a more thorough procedure for practical safety management, allowing the achievement of solutions closer to the safety needs of workers [46]. From these considerations, the need to augment the research on the factors influencing the unsafe behavior of workers in the construction industry considering human reliability issues emerges, given that these aspects are strictly related to safety climate [47]. The review of the previous studies in this field revealed a gap in the literature concerning the analysis of human errors to better understand human interaction with working tasks, augmenting the safety climate by means of a bottom-up approach. In particular, an approach aimed at facilitating this type of analysis by SMEs operating in this sector has not been investigated sufficiently.

\section{Research Approach}

To reduce the abovementioned gap, the study focused on the behavioral side of the safety climate, following a bottom-up approach, which starts from the identification of potential hazardous situations and events to define human behavior improvements, as suggested by Glendon and Stanton [20]. On this, a procedure based on the Job Safety Assessment (JSA) approach was developed, as it represents one of the most prevalent procedures used in the construction industry for safety assessment due to its easiness of use [48]. Then, to achieve a more human-centered approach, its augmentation through more specific safety practices was considered [49].

In particular, attention was focused on those widespread tools presenting a low level of difficulty for their implementation, such as: Hierarchical Task Analysis (HTA), Predictive Human Error Analysis (PHEA) (also known as Systematic Human Error Reduction and Prediction Approach (SHERPA)), and Human Error Assessment and Reduction Technique (HEART) [50].

In other words, our procedure (called Preliminary Human Safety Assessment (PHSA)) can be considered as an improvement of the JSA approach by means of its integrated and coordinated use of tools for investigating workers' behavior and their likelihood towards errors when performing a specific working activity, as schematized in Figure 1. 


\begin{tabular}{|c|c|c|}
\hline PHSA phases & PHSA tools & Expected outputs \\
\hline $\begin{array}{l}1 . \\
\text { CONTEXT } \\
\text { DEFINITION }\end{array}$ & $\begin{array}{c}\text { Interviews, accidents' } \\
\text { statistics }\end{array}$ & $\begin{array}{l}\text { Information concerning the } \\
\text { working tasks on sites }\end{array}$ \\
\hline $\begin{array}{l}2 . \\
\text { TASK'S STEPS } \\
\text { DEFINITION }\end{array}$ & HTA & $\begin{array}{l}\text { Hierarchy of working tasks } \\
\text { and their steps }\end{array}$ \\
\hline $\begin{array}{l}3 . \\
\text { HAZARDS } \\
\text { IDENTIFICATION }\end{array}$ & $\begin{array}{l}\text { Standards, interviews, } \\
\text { accidents' statistics }\end{array}$ & $\begin{array}{l}\text { Hazardous situations and } \\
\text { events are linked to the } \\
\text { working activities }\end{array}$ \\
\hline $\begin{array}{l}4 . \\
\text { HUMAN ERRORS } \\
\text { IDENTIFICATION }\end{array}$ & PHEA & $\begin{array}{c}\text { Possible errors are related to } \\
\text { working activities }\end{array}$ \\
\hline $\begin{array}{l}5 . \\
\text { HUMAN ERROR } \\
\text { ASSESSMENT }\end{array}$ & Interviews, HEART & $\begin{array}{l}\text { Ranking of main errors for } \\
\text { each working step }\end{array}$ \\
\hline $\begin{array}{l}6 . \\
\text { IMPROVEMENTS } \\
\text { DEFINITION }\end{array}$ & $\begin{array}{l}\text { PHEA, standards, } \\
\text { guidelines }\end{array}$ & $\begin{array}{l}\text { Safety improvement options, } \\
\text { augmented knowledge on the } \\
\text { safe bahavior among workers }\end{array}$ \\
\hline \multicolumn{3}{|c|}{$\begin{array}{l}\text { Note: } \\
\text { HTA = Hierarchical Task Analysis; } \\
\text { PHEA = Predictive Human Error Analysis; } \\
\text { HEART = Human Error Assessment and Reduction Technique. }\end{array}$} \\
\hline
\end{tabular}

Figure 1. Scheme of the Preliminary Human Safety Assessment (PHSA) procedure.

More in detail, the main phases of the PHSA procedure are the following:

1. Context definition: In this phase, to better define the characteristics of the working task, interviews with workers and safety managers are carried out, also considering the company's historical data concerning accidents and critical situations (near-miss accidents included).

2. Tasks' steps definition: Based on the information collected in the previous phase, the working tasks are split into sub-tasks and elementary activities. In fact, although the latter may not be complex in and of themselves, the working task is complex, as it consists of interrelated elementary activities that might influence each other [51]. For this purpose, the HTA method was used, allowing the sub-division of working tasks into sub-tasks and elementary activities in a hierarchical manner.

3. Hazards identification: For each elementary activity, hazard types are identified, considering requirements of safety regulations and technical standards. In addition, information collected from the operators can also be useful. For example, analyzing the way a specific activity is carried out and/or the frequency of events that can affect the performances of the workers can allow engineers to pinpoint potential errors and consequently potential hazardous situations and events [52].

4. Human error identification: The potential hazardous situations/events can be associated with the possible errors by means of the PHEA/SHERPA method, which can provide a distinction of the possible human failures in six main categories [53]:

- Action errors (A), when the human action changes the status of the system;

- Checking errors $(C)$, when the operator fails to verify, check the status of the system;

- Retrieval errors (R), if the operator fails to retrieve information, e.g., from a working procedure; 
- Transmission errors (T), when the operator fails to transfer information to other personnel;

- Selection errors (S), when the operator makes the wrong choice among different alternatives;

- Planning errors $(\mathrm{P})$, are related to procedures not updated or incorrect, or if the training of workers is inadequate.

5. Human error assessment: To evaluate the potential errors better, reducing the criticalities concerning the likelihood of the PHEA's outputs highlighted by Ainsworth [54], the HEART method was used to evaluate the error probabilities for each working activity, allowing an efficiency of resources compared to other widely used HRA tools [55]. In detail, the assessment of the human error probability index ( $\mathrm{I}_{\mathrm{ERR}}$ ) associated to each activity is carried out by means of the following equation:

$$
\mathrm{I}_{\mathrm{ERRi}}=\mathrm{P}_{0 \mathrm{i}} \times \mathrm{PF}_{\mathrm{i}}=\mathrm{P}_{0 \mathrm{i}} \times \prod_{\mathrm{ij}} \mathrm{PF}_{\mathrm{ij}}
$$

where $P_{0 \mathrm{i}}$ represents the nominal human unreliability value associated to the i-th activity, while $\mathrm{PF}_{\mathrm{i}}$ represents the product of the performance factors for the i-th activity. To estimate the latter, the error producing conditions (EPCs) are introduced: considering each activity, a set of EPCs can reduce the performances of the operator while carrying it out. The relationship between the performance factors and the error producing conditions can be assessed through the following equation:

$$
\mathrm{PF}_{\mathrm{ij}}=\left[\left(\mathrm{EPC}_{\mathrm{ij}}-1\right) \times \mathrm{Ap}_{\mathrm{i}}\right]+1,
$$

where $\mathrm{EPC}_{\mathrm{j}}$ is the $\mathrm{j}$-th error promoting condition, while $\mathrm{Ap}_{\mathrm{i}}$ represents the proportion assessment factor, i.e., the evaluation of the proportion of each $\mathrm{EPC}_{\mathrm{ij}}$ existing in the activity being assessed [23]. In other words, given a certain number $i$ of activities $(i=1,2, \ldots, n)$, for each $i$-th activity a set of $j$ EPCs can be defined $(j=1,2, \ldots, m)$. Hence, the definition of the related set of $\mathrm{PF}_{\mathrm{ij}}$ is performed through Equation (2), whose product is computed by means of Equation (1). The estimation of both $\mathrm{P}_{0}$ and EPCs can be made considering specific tables that provide a list of nominal human unreliability and error-promoting conditions, with suggested values for each $\mathrm{P}_{0}$ and EPCs. As far as the latter are concerned, to better balance the assessment and reduce pessimistic results, assessors are usually asked to select a limited number of EPCs. For example, Williams [56] suggested using no more than three EPCs $(j=3)$, representing the three most relevant sources of human reliability for each activity (in Appendix B, an excerpt of the EPCs list from Reference [56] is provided). Then, for each activity, engineers estimate $A p_{i}$ whole value ranges from 0 to 1 depending on the extent to which the effect of the EPCs deviate from the ideal value of 1 . For example, a value of 0.3 is given to $A p_{i}$ when they evaluate that 30 percent of the full effect of inexperience can be present (i.e., the operator is not completely inexperienced).

6. Definition of possible improvements: To deal with the outputs emerging from the previous steps, preventive and protective measures are defined. Analyzing both the error types and the EPCs, a more detailed picture on the safety perception within the company can be drawn. Moreover, the use of the PHEA tables depicting error types, consequences, and error reduction/prevention measures allows safety managers to gather useful information to adopt remedial measures augmenting the safety level and safety climate within the company.

\section{Case Study}

To verify the effectiveness of the PHSA approach, a practical case study was carried out in collaboration with two SMEs operating in the construction industry in Italy, specializing in the distribution of different types of concretes and powders used in construction sites. Specifically, the analysis was focused on the use of in-transit concrete mixers. It has to be noted that a larger number of companies was contacted, but in the end only two of them provided full collaboration. Such a behavior reflects the hindrances of SMEs in approaching safety issues [57], as well as the low rate of participation observed by Gobo [58]. 


\subsection{Context Definition}

In this phase, interviews with the workers were carried out to collect the information concerning the working task, including the working procedures (i.e., the safety instructions) provided by the company, the manuals for the equipment, the training programme of the operators, etc. More in detail, 13 operators belonging to Company " $\mathrm{A}$ " and five operators from Company " $\mathrm{B}$ " were interviewed, as well as the two safety managers. Although the total number of interviewees was not large, it can be considered in line with the average of the sampling size suggested in studies on qualitative case-study research [59].

Interviews were carried out separately and the results were kept anonymous to reduce the possibility of biasing the responses. For instance, the operators were asked to provide a response to the following questions: "Could you describe the sequence of the main activities carried out in a working day?"; "Could you provide details on how activity X is performed?"; "In your experience, which are the main problems you have to deal with when performing the X activity?"; etc. Accordingly, information regarding how the concrete mixers were used (i.e., all the steps of the working activity considering the usual operations, as well as peculiar situations that happened in the past) were gathered. The interviews concerned also the different working situations that the operators have to deal with when operating at the construction sites (e.g., the different ways of discharging the material, the possible interferences due to the presence of other workers/equipment, etc.). It has to be noted that both companies use concrete mixer trucks and concrete mixer pump trucks. In this study, the former equipment was considered to make the usability of our analysis larger, since concrete mixer trucks are more widespread.

\subsection{Tasks' Steps Definition}

Based on the information collected in the previous phase, the HTA method was applied, dividing the working task "use of the concrete mixer" into sub-tasks. In particular, each sub-task was decomposed into elementary activities: in this case study, the sub-tasks were four, while the elementary activities were nine, as shown in Figure 2.

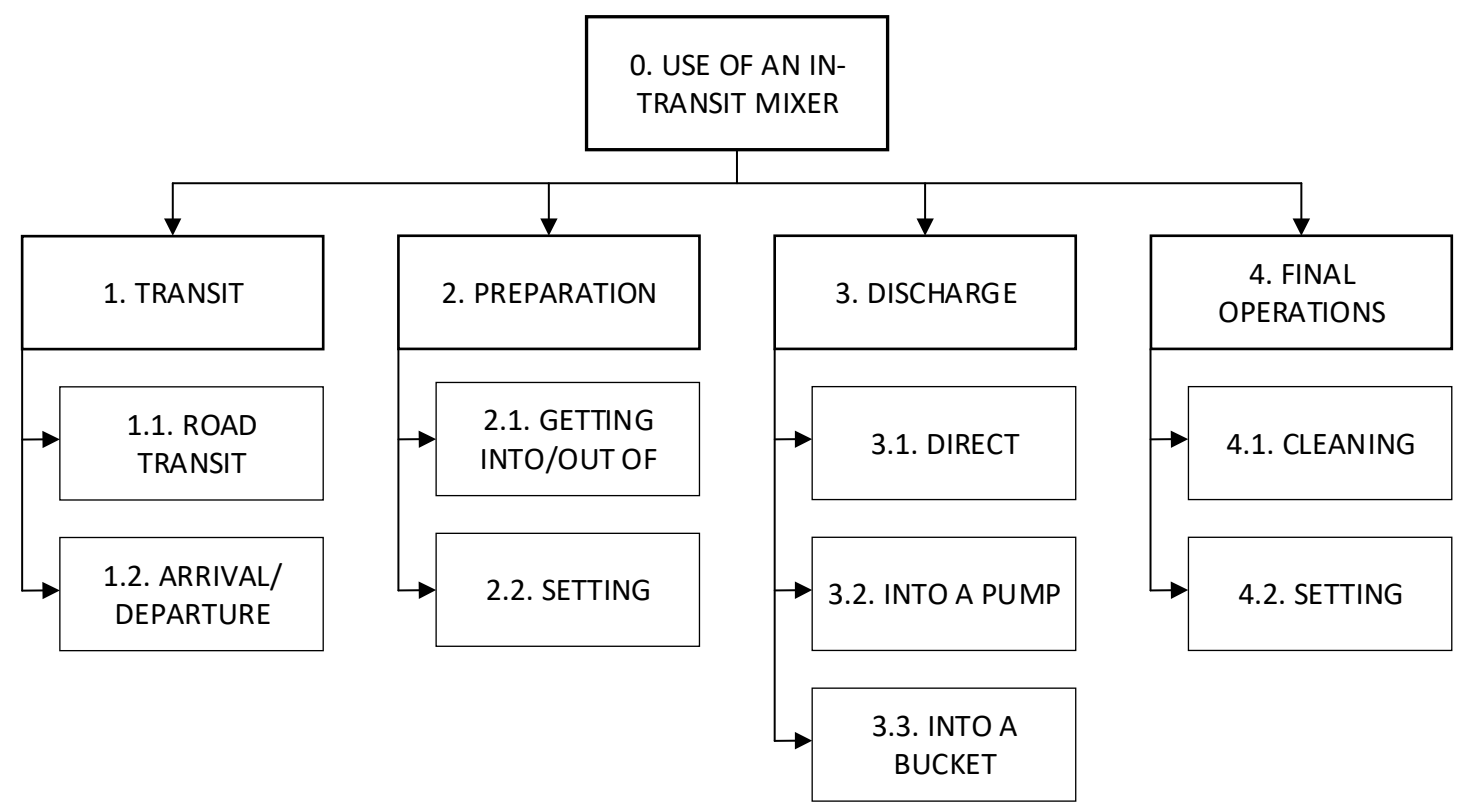

Figure 2. Application of the hierarchical task analysis (HTA) method. 


\subsection{Hazards Identification}

The starting point of this stage consisted of the analysis of standards related to machinery safety: in our case the Italian standard UNI 11464:2012 [60] concerning safety requirements of truck mixers was taken into account. In addition, also accidents statistics related to the use of truck mixers were considered to better individuate hazardous events and situations. Then, interviews with the safety managers were organized to refine the list of hazards, and to associate them with the elementary activities previously defined. The final output is summarized in Table 1, while a complete list of the hazardous situations/events is reported in Appendix A.

Table 1. List of hazardous situations/events related to each activity.

\begin{tabular}{|c|c|c|}
\hline No. & Activities & Hazardous Events \\
\hline A.1.2 & Driving in the construction site & $\begin{array}{l}\text { Collision with other vehicles/equipment; Crushing due to loss of stability (e.g., } \\
\text { truck roll-over); Exposure to dust and hazardous substances; Contact with } \\
\text { electrical parts; Collision with other workers. }\end{array}$ \\
\hline A.2.1 & Getting into/out of the cabin & Slipping, Low falls; Contact with heated parts. \\
\hline A.3.1 & Concrete direct discharge & $\begin{array}{l}\text { Crushing due to loss of stability; Impacts and crushing due to the fall of } \\
\text { material/objects; Slipping, Low falls. }\end{array}$ \\
\hline A.3.2 & Concrete discharge into a pump & $\begin{array}{l}\text { Crushing due to loss of stability; Impacts and crushing due to the fall of } \\
\text { material/objects; Slipping, Low falls; Entanglement, trapping; Contact with } \\
\text { electrical parts; Exposure to dust and hazardous substances; Handling of heavy } \\
\text { objects; Impact with ejected material. }\end{array}$ \\
\hline A.3.3 & Concrete discharge into a bucket & $\begin{array}{l}\text { Crushing, impacts due to the equipment mobility; Impact with ejected material; } \\
\text { Impacts and crushing due to the fall of material/objects. }\end{array}$ \\
\hline A. 4.1 & Cleaning the drum & $\begin{array}{l}\text { Falls from heights; Severing, cutting; Slipping, low falls, trips; Impacts; } \\
\text { Projection of high-pressure fluids/materials; Contact with electrical parts. }\end{array}$ \\
\hline A.4.2 & Maintenance and final setting & Slipping, low falls, trips; Falls from heights; Severing, cutting; Impacts. \\
\hline
\end{tabular}

\subsection{Human Errors Identification}

The PHEA/SHERPA method was applied to identify the human failure types for each activity. In more detail, in collaboration with the safety managers, for each activity a list of errors was defined based on the information provided by the operators. Then, they were classified using as reference for the error types' sub-categories the list provided by Embrey [23].

For instance, A.2 stands for "Action mis-timed", S.2 represents "Wrong selection made", while R.3 is "Information retrieval incomplete". In Table 2, an excerpt of this application is shown.

Table 2. Excerpt of the Predictive Human Error Analysis (PHEA/SHERPA) application.

\begin{tabular}{|c|c|c|c|}
\hline Code & Activity & Description of the Error & Error Type \\
\hline \multirow{6}{*}{1.2} & \multirow{6}{*}{$\begin{array}{l}\text { Driving on the } \\
\text { construction site }\end{array}$} & The operator chooses a wrong route in the construction site. & S.2 \\
\hline & & The operator does not follow the traffic signs. & R.3 \\
\hline & & The operator uses the established traffic patterns for trucks. & A. 2 \\
\hline & & The operator does not use the safety signs (e.g., the rotating beacon). & A. 8 \\
\hline & & The operator drives under suspended loads. & A. 2 \\
\hline & & The operator does not verify the presence of power lines. & C.1 \\
\hline \multirow{2}{*}{2.1} & \multirow{2}{*}{$\begin{array}{l}\text { Getting into/out of } \\
\text { the cabin }\end{array}$} & The operator does not wear the Personal Protective Equipment (PPE). & A. 8 \\
\hline & & The operator does not follow the instructions. & R.3 \\
\hline \multirow{6}{*}{2.2} & \multirow{6}{*}{$\begin{array}{l}\text { Parking and setting at } \\
\text { the working place }\end{array}$} & The operator does not verify the type of soil when parking. & C.1 \\
\hline & & The operator does not follow the instructions on the parking place. & R.3 \\
\hline & & The operator does not apply the parking brake. & A. 8 \\
\hline & & The operator does not consider the information provided by bystander workers. & A. 8 \\
\hline & & The operator does not verify the presence of power lines. & C.1 \\
\hline & & The operator does not respect the minimum safety distances from the working area/other equipment. & A.7 \\
\hline
\end{tabular}

Note: The error types refer to the following categories: $\mathrm{A}=$ Action errors; $\mathrm{C}=$ Checking errors; $\mathrm{R}=\mathrm{Retrieval}$ errors; $\mathrm{T}=$ Transmission errors; $\mathrm{S}=$ Selection errors; $\mathrm{P}=$ Planning errors. Error types subcategories were depicted from Embrey [23] (p 163). 


\subsection{Human Error Assessment}

The HEART method was applied, considering an average value of 0.3 for $A p_{i}$ since all operators have a minimum of 5 years' experience in driving the concrete mixer in the construction industry with the same company. The performance factors of each activity were calculated by means of Equation (2). It is worth noting that in this study the three most relevant EPCs for each activity resulting from the interviews were considered as discussed in the previous section. Hence, while the number of activities was $n=9$, the number of EPCs was $m=3$.

More in detail, the selection of the EPCs for each activity was performed by means of an ad-hoc questionnaire: with the support of safety managers, the list of EPCs reported in Appendix B was explained to the operators. Then, they were asked to select for each activity the three most relevant error-producing conditions that might affect the behavior of the operator.

Finally, considering the worst and the best end of the range of each of the EPCs emerging during the interviews as suggested by Embrey [23], the list of EPCs was defined and the performance factors for each activity were calculated. The results of this analysis are reported in Table 3, where the number of the EPCs is referred to in the list in Appendix B.

Table 3. Computation of the performance factors (PFs) for each activity $\left(\mathrm{PF}_{\mathrm{i}}\right)$.

\begin{tabular}{|c|c|c|c|}
\hline Activities & $\begin{array}{l}\text { No. of Error Producing } \\
\text { Conditions (EPCs) }\end{array}$ & $\begin{array}{c}\text { Elementary Performance } \\
\text { Factors }\left(\mathrm{PF}_{\mathrm{ij}}\right)\end{array}$ & $\begin{array}{c}\text { Activity Performance } \\
\text { Factor }\left(\mathrm{PF}_{\mathrm{i}}\right)\end{array}$ \\
\hline \multirow{3}{*}{$\begin{array}{l}1.1 \text { Road transit to reach } \\
\text { the construction site }\end{array}$} & 7 & {$[(8-1) \times 0.3]+1=3.1$} & \multirow{3}{*}{9.42} \\
\hline & 12 & {$[(3-1) \times 0.3]+1=1.9$} & \\
\hline & 17 & {$[(3-1) \times 0.3]+1=1.6$} & \\
\hline \multirow{3}{*}{$\begin{array}{l}\text { 1.2. Driving on the } \\
\text { construction site }\end{array}$} & 2 & {$[(11-1) \times 0.3]+1=4$} & \multirow{3}{*}{14.08} \\
\hline & 11 & {$[(5-1) \times 0.3]+1=2.2$} & \\
\hline & 16 & {$[(3-1) \times 0.3]+1=1.6$} & \\
\hline \multirow{3}{*}{$\begin{array}{l}\text { 2.1. Getting into/out of } \\
\text { the cabin }\end{array}$} & 2 & {$[(11-1) \times 0.3]+1=4$} & \multirow{3}{*}{12.16} \\
\hline & 12 & {$[(4-1) \times 0.3]+1=1.9$} & \\
\hline & 16 & {$[(3-1) \times 0.3]+1=1.6$} & \\
\hline \multirow{3}{*}{$\begin{array}{l}\text { 2.2. Parking and setting } \\
\text { at the working place }\end{array}$} & 2 & {$[(11-1) \times 0.3]+1=4$} & \multirow{3}{*}{12.44} \\
\hline & 12 & {$[(4-1) \times 0.3]+1=1.9$} & \\
\hline & 14 & {$[(4-1) \times 0.3]+1=1.9$} & \\
\hline \multirow{3}{*}{$\begin{array}{l}\text { 3.1. Concrete direct } \\
\text { discharge }\end{array}$} & 7 & {$[(8-1) \times 0.3]+1=3.1$} & \multirow{3}{*}{10.91} \\
\hline & 11 & {$[(5-1) \times 0.3]+1=2.2$} & \\
\hline & 16 & {$[(3-1) \times 0.3]+1=1.6$} & \\
\hline \multirow{3}{*}{$\begin{array}{l}\text { 3.2. Concrete discharge } \\
\text { into a pump }\end{array}$} & 7 & {$[(8-1) \times 0.3]+1=3.1$} & \multirow{3}{*}{8.54} \\
\hline & 13 & {$[(4-1) \times 0.3]+1=1.9$} & \\
\hline & 19 & {$[(2.5-1) \times 0.3]+1=1.45$} & \\
\hline \multirow{3}{*}{$\begin{array}{l}\text { 3.3. Concrete discharge } \\
\text { into a bucket }\end{array}$} & 7 & {$[(8-1) \times 0.3]+1=3.1$} & \multirow{3}{*}{9.42} \\
\hline & 13 & {$[(4-1) \times 0.3]+1=1.9$} & \\
\hline & 16 & {$[(3-1) \times 0.3]+1=1.6$} & \\
\hline \multirow{3}{*}{ 4.1. Cleaning the drum } & 7 & {$[(8-1) \times 0.3]+1=3.1$} & \multirow{3}{*}{11.19} \\
\hline & 12 & {$[(4-1) \times 0.3]+1=1.9$} & \\
\hline & 14 & {$[(4-1) \times 0.3]+1=1.9$} & \\
\hline \multirow{3}{*}{$\begin{array}{l}\text { 4.2. Maintenance and } \\
\text { final setting }\end{array}$} & 6 & {$[(8-1) \times 0.3]+1=3.1$} & \multirow{3}{*}{9.42} \\
\hline & 12 & {$[(4-1) \times 0.3]+1=1.9$} & \\
\hline & 16 & {$[(3-1) \times 0.3]+1=1.6$} & \\
\hline
\end{tabular}

Accordingly, the human error probability index $\left(\mathrm{I}_{\mathrm{ERR}}\right)$ was calculated by means of Equation (1). The results of this assessment are summarized in Table 4, where the value of the nominal human unreliability value associated to the i-th activity $\left(\mathrm{P}_{0 \mathrm{i}}\right)$ was considered equal to 0.03 for all activities (i.e., "miscellaneous task" as per Williams [56]). Such a value was selected to take into account the large variability of the working conditions from one construction site to another. 
Table 4. Values of the human error probability index ( $\left.\mathrm{I}_{\mathrm{ERRi}}\right)$.

\begin{tabular}{lccc}
\hline \multicolumn{1}{c}{ Activities } & $\mathbf{P}_{\mathbf{0 i}}$ & $\mathbf{P F}_{\mathbf{i}}$ & $\mathbf{I}_{\mathbf{E R R} \mathbf{i}}$ \\
\hline 1.1 Road transit to reach the construction site & 0.03 & 9.42 & 0.28 \\
1.2. Driving on the construction site & 0.03 & 14.08 & 0.42 \\
2.1. Getting into/ out of the cabin & 0.03 & 12.16 & 0.36 \\
2.2. Parking and setting at the working place & 0.03 & 12.44 & 0.37 \\
3.1. Concrete direct discharge & 0.03 & 10.91 & 0.33 \\
3.2. Concrete discharge into a pump & 0.03 & 8.54 & 0.26 \\
3.3. Concrete discharge into a bucket & 0.03 & 9.42 & 0.28 \\
4.1. Cleaning the drum & 0.03 & 11.19 & 0.34 \\
4.2. Maintenance and final setting & 0.03 & 9.42 & 0.28 \\
\hline
\end{tabular}

\subsection{Definition of Improvement Measures}

The use of the HEART method provides practical information aimed at addressing the possible improvements considering human factor issues. In fact, considering the selected EPCs for each activity, it was possible to highlight the weakest points of the company safety management (in Table 5, the EPCs were gathered based on the number of times they were selected).

Table 5. Ranking of the selected EPCs.

\begin{tabular}{cc}
\hline EPC Type & No. of Selections \\
\hline 7. Irreversibility & 5 \\
12. Misperception of risk & 5 \\
16. Impoverished information & 5 \\
2. Time shortage & 3 \\
13. Poor feedback & 2 \\
14. Delayed/incomplete feedback & 2 \\
6. Mismatch & 1 \\
10. Knowledge transfer & 1 \\
11. Performance ambiguity & 1 \\
17. Inadequate checking & 1 \\
19. No diversity & 1 \\
\hline
\end{tabular}

For example, it emerged that the perception of risk (EPC no. 12 "Mismatch between perceived and actual risk") was a relevant problem together with the lack of effective procedures (EPC no. 16 "An impoverished quality of information conveyed by procedure and person to person interaction"), which can be reduced by means of specific training and information activities. Similarly, the EPC no. 7 ("no obvious means of reversing an unintended action") highlights a difficulty of operators in dealing with complex tasks, where an unintended error in using the equipment cannot be corrected easily. This EPC was selected for all those activities where the operators have to interact, directly or indirectly, with other personnel/equipment on the site (e.g., while discharging into a bucket/hopper managed by a different worker). The improvement measures in this case might concern: specific training and an update of the equipment (e.g., the use of a closed circuit television (CCTV) system and/or close proximity sensors), as well as safety procedures foreseeing the use of a banksman on the construction site. Accordingly, the use of the PHEA tables allows the definition of a recovery analysis to properly manage safety issues related to human behavior.

\section{Discussion of Results}

\subsection{Case Study Results}

The case study results have brought to light interesting aspects both from the risk-taking behavior and from the safety management point of view. To better analyze them, the output of the PHSA approach was used to augment the risk assessment that companies have to report to comply with 
occupational health and safety legislation. Based on these reports, the safety managers of both companies were asked to estimate the index of risk associated to each hazardous event according to a qualitative estimation of the indices representing the probability of occurrence of a certain event and the severity of its consequences [61]. In more detail, Equation (3) was used:

$$
\mathrm{I}_{\mathrm{RC}}=\mathrm{I}_{\mathrm{O}} \times \mathrm{I}_{\mathrm{S}},
$$

where $\mathrm{I}_{\mathrm{O}}$ represents the index of probability of an initiating hazardous event (i.e., the probability of occurrence of a hazardous situation/event), $\mathrm{I}_{\mathrm{S}}$ indicates the index of severity (i.e., the damage of consequences), and $\mathrm{I}_{\mathrm{RC}}$ the risk index obtained in such a conventional manner. The estimation of $\mathrm{I}_{\mathrm{O}}$ and $\mathrm{I}_{\mathrm{S}}$ was performed using the following criteria: $\mathrm{I}_{\mathrm{O}}$ was evaluated using a scale ranging from $1=$ very unlikely to 5 = very likely; IS was estimated taking into account a 1 to 5 scale, where 1 corresponds to minor effects (e.g., injuries recoverable in 1 day), while 5 corresponds to catastrophic effects (e.g., death or permanent injuries). To include human error concerns, the risk level of each elementary activity was augmented considering the human error probability ( $\mathrm{P}_{\mathrm{ERR}}$ ) obtained through Equation (1). In practice, the new risk index $\left(\mathrm{I}_{\mathrm{PHSA}}\right.$ ) was obtained through the following equation:

$$
\mathrm{I}_{\mathrm{PHSA}}=\mathrm{I}_{\mathrm{ERR}} \times \mathrm{I}_{\mathrm{RC}}=\mathrm{I}_{\mathrm{ERR}} \times \mathrm{I}_{\mathrm{O}} \times \mathrm{I}_{\mathrm{S}},
$$

The output of this analysis is shown in Figure 3, where for each hazardous event (HE) (listed in Appendix A) the dotted line represents the risk index considering the PHSA approach ( I $_{\text {PHSA }}$ ), while the solid line indicates the risk index following the conventional approach $\left(\mathrm{I}_{\mathrm{RC}}\right)$.

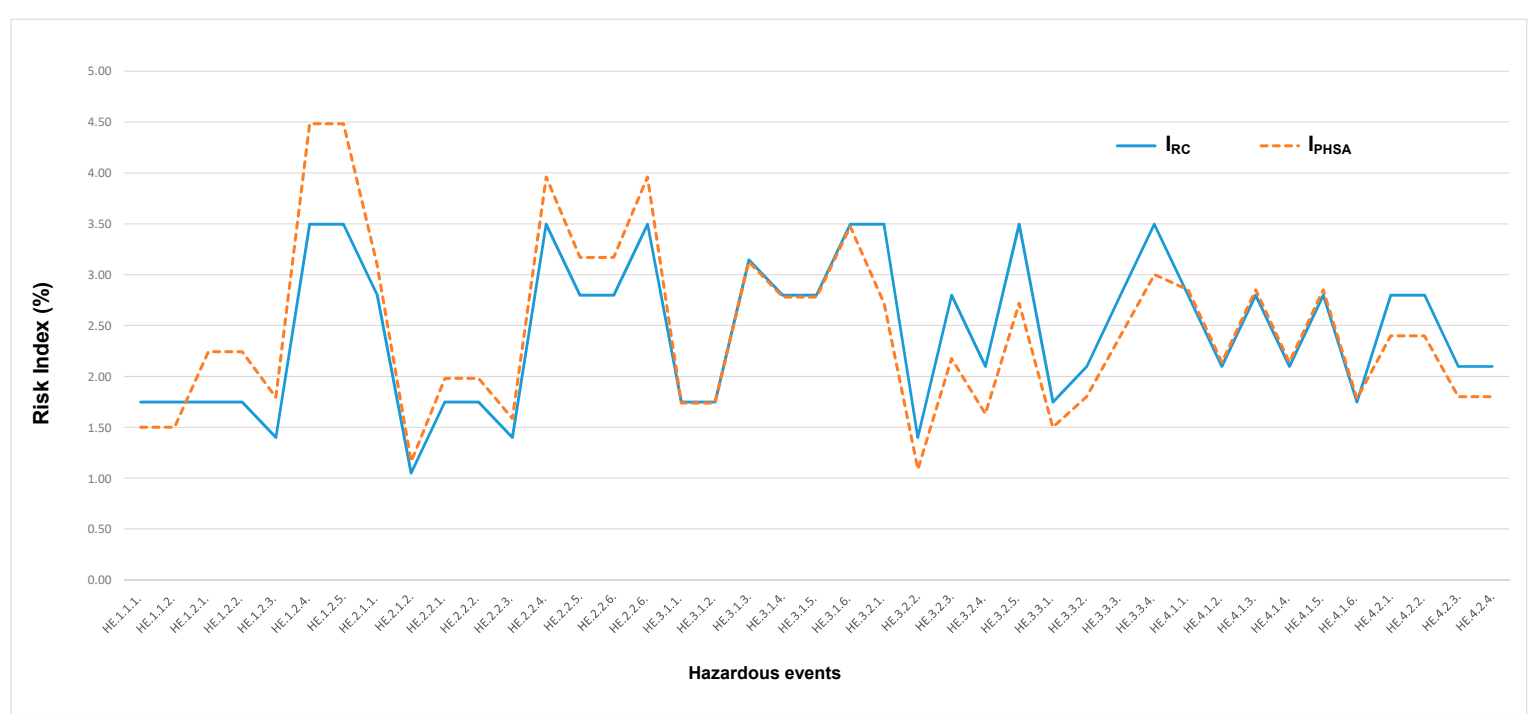

Figure 3. Comparison between the risk index considering the conventional $\left(\mathrm{I}_{\mathrm{RC}}\right)$ and PHSA

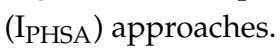

Although the general trend of the risk index was very similar, it can be observed that the PHSA approach provides a higher difference between the maximum and the minimum level, allowing a clearer differentiation between one risk and the others (i.e., the scores vary in a wider range of values). This aspect is consistent with Bohm and Harris [62], who stressed the importance of providing a higher scoring "resolution" than the one obtained through the conventional risk assessment, in order to bring to light the risk-taking behavior and perception of dumper drivers operating on construction sites.

The impact of human reliability emerges especially for less standardized activities such as "getting into/out of the truck's cabin", and for more complex ones such as "driving on the construction site", where the time pressure and the presence of other personnel and equipment make the probability of failing higher. In these situations, "contact with electrical parts" (HE.1.2.4) and "collision with other 
workers" (HE.1.2.5) appeared as the most probable events, bringing to light the perception of unsafe working conditions of the operators. Similarly, when the operator has to deal with the direct discharge of concrete, the level of risks was more significant taking into account the human error possibilities. These results are in line with the statistics concerning accidents while using a concrete mixer that occurred in Italy during the period from 2002-2015 [63].

\subsection{Effectiveness of the Proposed Approach}

From a more general perspective, it is worth noting that the PHSA procedure allows safety managers to consider the variability of working situations. In fact, while a conventional risk-assessment approach, relying on the analysis of the consequences of accidents (top-down approach) provide similar evaluations for the same hazardous events, the PHSA can provide helpful information on when human performances might lead to a more or less likely accident, given the same type of hazardous event. Thus, following a bottom-up approach for risk identification and assessment provides more comprehensive and thorough results than a top-down approach [64].

Thus, the proposed approach can support safety managers in the preliminary characterization of risk scenarios [65], augmenting the effectiveness of prevention measures at the task level [54]. Hence, the results gained through the PHSA approach can be used as input for a further investigation on the causalities related to the human performances, which is a key element in the prevention of construction accidents [66]. Such a finding also complements recent studies on the application of the resilience engineering (RE) approach, underlining that in a dynamic system (such as a construction site), human performance can drift outside of acceptable tolerances $[67,68]$.

According to human behavior analysis, the proposed approach is based on the analysis of the operators' feedback, whose involvement has a positive impact on the safety climate at the company level [69], favoring the implementation of safer solutions from both the management and the engineering point of view [70]. The participatory nature of the PHSA method, in fact, allows safety managers to better understand the workers' safety problems and consequently to adopt more human-centered solutions [71].

In this regard, a noteworthy aspect concerns the underestimation of potential risks by the operators since about $40 \%$ of them judged driving activities (both on the road and on the construction site) as routine operations, which do not need specific procedures. This result was confirmed from the analysis of EPCs (Table 5), showing a general lack of awareness of the risks due to misperception (EPCs no. 6, 12, and 16), in line with the findings highlighted by Man et al. [72]. Such an output can be considered even more consistent since, unlike the sample interviewed by the latter, in our context all the interviewed operators can be considered "qualified" or "experts" in their job having at least 5 years of experience. Additionally, the results of the PHEA method brought to light that the majority of errors belong to the Action errors type (A.2 "Action mistimed" and A.8 "Action omitted") and to the Retrieval errors (R.3 "Information retrieval incomplete"). This implies that the companies have to focus on increasing their capability in information and communication activities, providing effective procedures for a continuous monitoring of the workers' feedback. Consequently, a general improvement of organizational factors by means of specific measures suitable for the company size and dimensions is needed, as for instance the implementation of a simplified safety management system [73] or the use of a safety knowledge management tool [74]. Overall, PHSA is based on the extension of the JSA method by means of HRA tools. In this regard, it should be noted that due to the complexity of the activities carried out on a construction site, the use of JSA might result in being less effective than in other contexts [75]. The integrated approach proposed in this study can contribute to reduce this weakness, augmenting the JSA's effectiveness and usability. In fact, while JSA plays a strategic role within the PHSA procedure, providing information on the proper sequence of the activities that safety managers have to carry out, the HRA tools support them in performing these activities in an effective manner. Accordingly, the PHSA procedure can contribute to the body of knowledge on JSA in dealing 
with the analysis of complex systems, in line with the suggestions provided by Rozenfeld et al. [48], making the number of its potential users larger.

\subsection{Practical Benefits of the Method}

Based on the above considerations, the practical contributions of this study in the context of safety management in the construction industry can be synthesized as follows:

- Compared to top-down studies, the proposed bottom-up approach for the analysis of human safety performances allows a clearer perception of hazards and risk-taking behaviors of workers, affecting safety climate positively, as it can impact on workers more directly.

- The inclusion of human reliability tools in the safety assessment of working activities is not a novelty in the extant literature. However, the PHSA procedure can augment practical knowledge on the integrated and coordinated use of these methods in the construction sector, providing a basis for further developments by means of researchers and practitioners.

- The results of the case study highlighted the higher probability of human failures when working activities are carried out under time pressure and when interacting with workers from different companies, confirming the outputs of the prevalent studies in this field. Hence, despite the qualitative nature of the procedure, its use resulted in being beneficial to prevent human errors, addressing safety managers in adopting more effective improvement options (e.g., specific training and working procedures).

- In small-sized companies, behavioral aspects of safety climate appeared underestimated, affecting the risk level of operators negatively. The proposed procedure represents an easy-to-use tool to evaluate and monitor the workers' unsafe behavior in these contexts.

Overall, the PHSA procedure can be intended as a guidance for safety managers to analyze and monitor behavioral aspects of safety climate, improving safety management activities in an effective manner in SMEs operating in the construction industry. Accordingly, to reduce the efforts for its implementation, the proposed procedure is based on the use of well-known and widespread tools. Hence, the value of the study can be individuated in their integrated and coordinated use at a practical level. Such an approach is consistent with Khosravi et al. [22], who observed that integrating different qualitative and mixed risk-assessment tools is useful for understanding workers' perception of safety and risk.

\subsection{Limitations}

Beside these positive aspects, the limitations of this paper also need to be discussed. Firstly, the limited number of interviewed people (20 in total) reduces the external validity of the study. Hence, while its outputs can be considered as a basis to generate new understandings and while the type of results achieved can be considered exploratory and used to generate new understandings, prudence is required in generalizing the findings [76], and further applications of the proposed procedure, also in different contexts, is needed to extend their validity [77].

From the implementation point of view, compared to the traditional job safety assessment, the use of the PHSA procedure certainly requires additional efforts, especially for what concerns the time spent for the interviews. In this ambit, the most time-consuming activity concerned the definition of the EPCs (step 4.5 of the procedure). However, this aspect is expected to become less resource consuming with experience, as noted by Huges et al. [78]. Moreover, it is worth noting that in order to comply with occupational health and safety (OHS) requirements, risk-assessment activities have to consider statistics on occupational accidents and technical standards, as well as to include the participation of workers [79]. Hence, most of the information needed to apply the PHSA procedure should already be at the disposal of safety managers, limiting the amount of resources needed for its application. Nevertheless, it has to be also underlined that the difficulty of implementation of the procedure can increase when different working tasks are carried out (e.g., in larger sized companies). In this regard, the effectiveness of the PHSA needs to be further verified. 
Moreover, this study was focused on the behavioral aspects of safety climate, while organizational issues were not considered as they are beyond the goal of this paper. However, to depict a more thorough framework, questionnaires concerning organizational issues should be considered. In addition, the present study took into account several methods based on their diffusion and easiness of use, mainly considering their usability in the SMEs' context, by non-specialists [29]. However, such a selection cannot be considered exhaustive and further investigation on the systematic use of other HRA tools in the PHSA procedure should be carried out to provide a more comprehensive analysis. Accordingly, the use of quantitative risk analysis models can provide better understandings of risk-related activities [80].

Finally, the vagueness and subjectivity of the results that characterize qualitative assessment approaches as in our case are worth noting. Hence, to reduce this limitation, the fuzzy set theory can be employed, as well as its augmentations [81].

\section{Conclusions}

Although in literature numerous studies exist on safety management in the construction industry, our proposition aimed at reducing the gap related to the analysis of factors influencing unsafe behaviors at the task level, i.e., focusing on the behavioral side of the safety climate by means of a bottom-up approach. Accordingly, a procedure to evaluate the impact of the operators' behavior when performing specific activities taking into account human reliability factors was proposed. A systematic application of this procedure, consisting of the integrated use of the HRA tool with the JSA method, to a real case study concerning the use of concrete mixer trucks was reported.

The study showed the interwoven relationship between human factors and safety management issues, providing practical cues to monitor and improve the safety climate at the company level. In particular, the study highlighted that the majority of errors occur when the operator: (1) changes the status of the system (Action errors); and (2) when the operator fails to follow a working procedure or safety information (Retrieval errors). As indicated in other studies reporting similar results in different contexts [82], both theoretical and practical training programs can be effective for reducing these types of errors, as well as a more effective and frequent communication with safety managers should be foreseen [83]. Besides, the results of the risk assessment showed that time pressure and the presence of other personnel on the construction site were the main contributors to unsafe behavior, suggesting the improvement of organizational factors. This aspect is quite critical in SMEs operating in the construction sector and ad-hoc solutions need to be developed.

Although the proposed use of different risk assessment tools was useful for understanding the workers' perception of risks, this study must be considered as an initial and qualitative step. Accordingly, further research work is needed to reduce the limitations mentioned in the previous section. In particular, the PHSA's application to other case studies should be considered in order to refine it and augment the external validity of these first results. In addition, the extension of the proposed procedure by means of different HRA tools should be investigated in order to provide more practical information on the use of human reliability analysis in the construction industry. Hence, researchers and practitioners are invited to contribute to the further development.

Author Contributions: Conceptualization, M.F., M.L.; methodology, M.F., M.L.; validation, M.F., M.L.; writing-review and editing, M.F., M.L.

Funding: This research received no external funding.

Conflicts of Interest: The authors declare no conflict of interest. 


\section{Appendix A}

Table A1. List of the hazardous situations/events (HEs).

\begin{tabular}{cl}
\hline \multicolumn{1}{c}{ Activities } & Hazardous events \\
\hline \multirow{2}{*}{ 1.1 Road transit to reach the construction site } & HE.1.1.1. Collision with other vehicles \\
& HE.1.1.2. Crushing due to loss of stability (e.g., truck roll-over) \\
\hline \multirow{2}{*}{ 1.2. Driving on the construction site } & HE.1.2.1. Collision with other vehicles/equipment \\
& HE.1.2.2. Crushing due to loss of stability (e.g., truck roll-over) \\
& HE.1.2.3. Exposure to dust and hazardous substances \\
& HE.1.2.4. Contact with electrical parts \\
& HE.1.2. Collision with other workers \\
\hline \multirow{2}{*}{ 2.1. Getting into/out of the cabin } & HE.2.1.1. Slipping, low falls, trips \\
& HE.2.1.2. Contact with heated parts \\
\hline \multirow{3}{*}{ 2.2. Parking and setting at the working place } & HE.2.2.1. Collision with other vehicles/equipment \\
& HE.2.2.2. Crushing due to loss of stability (e.g., truck roll-over) \\
& HE.2.2.4. Contact with electrical parts \\
& HE.2.2.5. Entanglement, trapping \\
& HE.2.2.6. Slipping, low falls, trips \\
& HE.2.2.6. Collision with other workers \\
\hline
\end{tabular}

HE.3.1.1. Crushing due to loss of stability

HE.3.1.2. Collision with other workers

3.1. Concrete direct discharge

HE.3.1.3. Impacts and crushing due to the fall of material/objects HE.3.1.4. Slipping, low falls, trips

HE.3.1.5. Handling of heavy objects

HE.3.1.6. Exposure to dust and hazardous substances

HE.3.2.1. Crushing, impacts due to other equipment mobility

HE.3.2.2. Entanglement, trapping

3.2. Concrete discharge into a pump

HE.3.2.3. Slipping, low falls, trips

HE.3.2.4. Impacts and crushing due to the fall of material/objects HE.3.2.5. Exposure to dust and hazardous substances

HE.3.3.1. Crushing, impacts due to other equipment mobility

3.3. Concrete discharge into a bucket HE.3.3.2. Impact with ejected material

HE.3.3.3. Slipping, low falls, trips

HE.3.3.4. Exposure to dust and hazardous substances

HE.4.1.1. Falls from heights

HE.4.1.2. Severing, cutting

4.1. Cleaning the drum

HE.4.1.3. Slipping, low falls, trips

HE.4.1.4. Impacts

HE.4.1.5. Projection of high-pressure fluids/materials

HE.4.1.6. Contact with electrical parts

HE.4.2.1. Slipping, low falls, trips

4.2. Maintenance and final setting

HE.4.2.2. Falls from heights

HE.4.2.3. Severing, cutting

HE.4.2.4. Impacts 


\section{Appendix B}

Table A2. The most used error-promoting conditions (EPCs) according to Williams [56].

\begin{tabular}{clc}
\hline No. & \multicolumn{1}{c}{ Error-Promoting Conditions (EPCs) } & Value \\
\hline 2 & Shortage of time for error detection or correction & 11 \\
3 & Noisy/confused signals & 10 \\
4 & A means of suppressing or overriding information & 9 \\
5 & No means of conveying spatial or functional information to human operator & 9 \\
6 & Poor system/human-user interface & 8 \\
7 & No obvious means of reversing an unintended action & 8 \\
8 & Information overload & 6 \\
9 & Technique unlearning/one which requires application of opposing philosophy & 6 \\
10 & Transfer knowledge from one task to another & 5 \\
11 & Ambiguity in required performance standard & 5 \\
12 & Mismatch between perceived and actual risk & 4 \\
13 & Poor, ambiguous or ill-matched feedback & 4 \\
14 & No clear/direct/timely confirmation of intended action from system & 4 \\
15 & Inexperience (newly qualified but not an expert) & 3 \\
16 & Poor instructions or procedures & 3 \\
17 & Little or no independent checking or testing of output & 3 \\
18 & No diversity of information input for veracity checks & 2.5 \\
\hline
\end{tabular}

\section{References}

1. Zhao, D.; Thabet, W.; McCoy, A.; Kleiner, B. Electrical deaths in the US construction: An analysis of fatality investigations. Int. J. Inj. Control. Saf. Prev. 2014, 21, 278-288. [CrossRef] [PubMed]

2. Dumrak, J.; Mostafa, S.; Kamardeen, I.; Rameezdeen, R. Factors associated with the severity of construction accidents: The case of South Australia. Constr. Econ. Build. 2013, 13, 32-49. [CrossRef]

3. Mahfuth, K.; Loulizi, A.; Al Hallaq, K.; Tayeh, B.A. Implementation Phase Safety System for Minimising Construction Project Waste. Buildings 2019, 9, 25. [CrossRef]

4. Cheng, C.W.; Leu, S.S.; Lin, C.C.; Fan, C. Characteristic analysis of occupational accidents at small construction enterprises. Saf. Sci. 2010, 48, 698-707. [CrossRef]

5. Carrillo-Castrillo, J.A.; Trillo-Cabello, A.F.; Rubio-Romero, J.C. Construction accidents: Identification of the main associations between causes, mechanisms and stages of the construction process. Int. J. Occup. Saf. Ergon. 2017, 23, 240-250. [CrossRef]

6. Harvey, E.J.; Waterson, P.; Dainty, A.R. Beyond ConCA: Rethinking causality and construction accidents. Appl. Ergon. 2018, 73, 108-121. [CrossRef]

7. Mitropoulos, P.; Cupido, G.; Namboodiri, M. Cognitive approach to construction safety: Task demand-capability model. J. Constr. Eng. Manag. 2009, 135, 881-889. [CrossRef]

8. Fargnoli, M.; Lombardi, M.; Haber, N.; Puri, D. The Impact of Human Error in the Use of Agricultural Tractors: A Case Study Research in Vineyard Cultivation in Italy. Agriculture 2018, 8, 82. [CrossRef]

9. Sousa, V.; Almeida, N.M.; Dias, L.A. Risk-based management of occupational safety and health in the construction industry-Part 1: Background knowledge. Saf. Sci. 2014, 66, 75-86. [CrossRef]

10. Di Pasquale, V.; Miranda, S.; Iannone, R.; Riemma, S. A simulator for human error probability analysis (SHERPA). Reliab. Eng. Syst. Saf. 2015, 139, 17-32. [CrossRef]

11. Sadeghi, L.; Mathieu, L.; Tricot, N.; Al Bassit, L. Developing a safety indicator to measure the safety level during design for safety. Saf. Sci. 2015, 80, 252-263. [CrossRef]

12. Llory, M. Human-and work-centred safety: Keys to a new conception of management. Ergonomics 1997, 40, 1148-1158. [CrossRef]

13. Chen, Y.; McCabe, B.; Hyatt, D. Impact of individual resilience and safety climate on safety performance and psychological stress of construction workers: A case study of the Ontario construction industry. J. Saf. Res. 2017, 61, 167-176. [CrossRef] [PubMed]

14. Gao, R.; Chan, A.P.; Utama, W.P.; Zahoor, H. Multilevel safety climate and safety performance in the construction industry: Development and validation of a top-down mechanism. Int. J. Environ. Res. Public Health 2016, 13, 1100. [CrossRef] [PubMed] 
15. Choudhry, R.M.; Fang, D.; Lingard, H. Measuring safety climate of a construction company. J. Contr. Eng. Manag. 2009, 135, 890-899. [CrossRef]

16. Mohammadi, A.; Tavakolan, M.; Khosravi, Y. Factors influencing safety performance on construction projects: A review. Saf. Sci. 2018, 109, 382-397. [CrossRef]

17. Dekker, S.W. Reconstructing human contributions to accidents: The new view on error and performance. J. Saf. Res. 2002, 33, 371-385. [CrossRef]

18. Jiang, Z.; Fang, D.; Zhang, M. Understanding the causation of construction workers' unsafe behaviors based on system dynamics modeling. J. Manag. Eng. 2014, 31, 04014099. [CrossRef]

19. Liao, P.C.; Lei, G.; Xue, J.; Fang, D. Influence of person-organizational fit on construction safety climate. J. Manag. Eng. 2013, 31, 04014049. [CrossRef]

20. Glendon, A.I.; Stanton, N.A. Perspectives on safety culture. Saf. Sci. 2000, 34, 193-214. [CrossRef]

21. Guo, B.H.; Yiu, T.W.; González, V.A. Identifying behaviour patterns of construction safety using system archetypes. Accid. Anal. Prev. 2015, 80, 125-141. [CrossRef] [PubMed]

22. Khosravi, Y.; Asilian-Mahabadi, H.; Hajizadeh, E.; Hassanzadeh-Rangi, N.; Bastani, H.; Behzadan, A.H. Factors influencing unsafe behaviors and accidents on construction sites: A review. Int. J. Occup. Saf. Ergon. 2014, 20, 111-125. [CrossRef]

23. Embrey, D. Qualitative and quantitative evaluation of human error in risk assessment. In Human Factors for Engineers; Sandom, C., Harvey, R.S., Eds.; IET: Hearts, UK, 2004; pp. 151-202, ISBN 0863413293.

24. Thevendran, V.; Mawdesley, M.J. Perception of human risk factors in construction projects: An exploratory study. Int. J. Proj. Manag. 2004, 22, 131-137. [CrossRef]

25. Islam, R.; Yu, H.; Abbassi, R.; Garaniya, V.; Khan, F. Development of a monograph for human error likelihood assessment in marine operations. Saf. Sci. 2017, 91, 33-39. [CrossRef]

26. Kirwan, B. Human error identification in human reliability assessment. Part 1: Overview of approaches. Appl. Ergon. 1992, 23, 299-318. [CrossRef]

27. Alvarenga, M.A.B.; Frutuoso e Melo, P.F.; Fonseca, R.A. A critical review of methods and models for evaluating organizational factors in Human Reliability Analysis. Progr. Nucl. Energ. 2014, 75, $25-41$. [CrossRef]

28. Strand, G.O.; Haskins, C. On Linking of Task Analysis in the HRA Procedure: The Case of HRA in Offshore Drilling Activities. Safety 2018, 4, 39. [CrossRef]

29. Kunlun, S.; Yan, L.; Ming, X. A safety approach to predict human error in critical flight tasks. Proc. Eng. 2011, 17, 52-62. [CrossRef]

30. Marhavilas, P.K.; Koulouriotis, D.; Gemeni, V. Risk analysis and assessment methodologies in the work sites: On a review, classification and comparative study of the scientific literature of the period 2000-2009. J. Loss Prev. Process. Ind. 2011, 24, 477-523. [CrossRef]

31. Mittal, A.; Sharma, H.K.; Mittal, K. Ergonomic risk controls in construction industry-A literature review. Int. J. Emerg. Res. Manag. Technol. 2013, 2, 28-33.

32. Su, X.; Pan, J.; Grinter, M. Improving construction equipment operation safety from a human-centered perspective. Proced. Eng. 2015, 118, 290-295. [CrossRef]

33. Choudhry, R.M. Behavior-based safety on construction sites: A case study. Accid. Anal. Prev. 2014, 70, 14-23. [CrossRef] [PubMed]

34. Li, H.; Lu, M.; Hsu, S.C.; Gray, M.; Huang, T. Proactive behavior-based safety management for construction safety improvement. Saf. Sci. 2015, 75, 107-117. [CrossRef]

35. Guo, B.H.; Goh, Y.M.; Wong, K.L.X. A system dynamics view of a behavior-based safety program in the construction industry. Saf. Sci. 2018, 104, 202-215. [CrossRef]

36. Wu, X.; Li, Y.; Yao, Y.; Luo, X.; He, X.; Yin, W. Development of construction workers job stress scale to study and the relationship between job stress and safety behavior: An empirical study in Beijing. Int. J. Environ. Res. Public Health 2018, 15, 2409. [CrossRef]

37. Seo, J.; Han, S.; Lee, S.; Kim, H. Computer vision techniques for construction safety and health monitoring. Adv. Eng. Inform. 2015, 29, 239-251. [CrossRef]

38. Zhou, Z.; Irizarry, J.; Li, Q. Applying advanced technology to improve safety management in the construction industry: A literature review. Constr. Manag. Econ. 2013, 31, 606-622. [CrossRef]

39. Zaira, M.M.; Hadikusumo, B.H. Structural equation model of integrated safety intervention practices affecting the safety behaviour of workers in the construction industry. Saf. Sci. 2017, 98, 124-135. [CrossRef] 
40. Guo, B.H.; Yiu, T.W.; González, V.A. Does company size matter? Validation of an integrative model of safety behavior across small and large construction companies. J. Saf. Res. 2018, 64, 73-81. [CrossRef] [PubMed]

41. Aneziris, O.N.; Topali, E.; Papazoglou, I.A. Occupational risk of building construction. Reliab. Eng. Syst. Saf. 2012, 105, 36-46. [CrossRef]

42. Fargnoli, M.; Lombardi, M.; Haber, N.; Guadagno, F. Hazard Function Deployment: A QFD based tool for the assessment of working tasks-A practical study in the construction industry. Int. J. Occup. Saf. Ergon. 2018, 1-53. [CrossRef] [PubMed]

43. Moaveni, S.; Banihashemi, S.Y.; Mojtahedi, M.A. Conceptual Model for a Safety-Based Theory of Lean Construction. Buildings 2019, 9, 23. [CrossRef]

44. Ye, G.; Tan, Q.; Gong, X.; Xiang, Q.; Wang, Y.; Liu, Q. Improved HFACS on Human Factors of Construction Accidents: A China Perspective. Adv. Civ. Eng. 2018, 2018, 1-15. [CrossRef]

45. Asilian-Mahabadi, H.; Khosravi, Y.; Hassanzadeh-Rangi, N.; Hajizadeh, E.; Behzadan, A.H. Factors affecting unsafe behavior in construction projects: Development and validation of a new questionnaire. Int. J. Occup. Saf. Ergon. 2018, 1-8. [CrossRef] [PubMed]

46. Zhou, Z.; Goh, Y.M.; Li, Q. Overview and analysis of safety management studies in the construction industry. Saf. Sci. 2015, 72, 337-350. [CrossRef]

47. Chen, Y.; McCabe, B.; Hyatt, D. A resilience safety climate model predicting construction safety performance. Saf. Sci. 2018, 109, 434-445. [CrossRef]

48. Rozenfeld, O.; Sacks, R.; Rosenfeld, Y.; Baum, H. Construction job safety analysis. Saf. Sci. 2010, 48, 491-498. [CrossRef]

49. Horberry, T.; Burgess-Limerick, R. Applying a human-centred process to re-design equipment and work environments. Safety 2015, 1, 7-15. [CrossRef]

50. Lyons, M. Towards a framework to select techniques for error prediction: Supporting novice users in the healthcare sector. Appl. Ergon. 2009, 40, 379-395. [CrossRef]

51. Shepherd, A. HTA as a framework for task analysis. Ergonomics 1998, 41, 1537-1552. [CrossRef]

52. Lombardi, M.; Fargnoli, M. Prioritization of hazards by means of a QFD-based procedure. Int. J. Saf. Secur. Eng. 2018, 8, 342-353. [CrossRef]

53. Harris, D.; Stanton, N.A.; Marshall, A.; Young, M.S.; Demagalski, J.; Salmon, P. Using SHERPA to predict design-induced error on the flight deck. Aerosp. Sci. Technol. 2005, 9, 525-532. [CrossRef]

54. Ainsworth, L.K. Task analysis. In Human Factors for Engineers; Sandom, C., Harvey, R.S., Eds.; IET: Hearts, UK, 2004; pp. 81-112, ISBN 0863413293.

55. Deacon, T.; Amyotte, P.R.; Khan, F.I. Human error risk analysis in offshore emergencies. Saf. Sci. 2000, 48, 803-818. [CrossRef]

56. Williams, J.C.; Bell, J.L. Consolidation of the error producing conditions used in the Human Error Assessment and Reduction Technique (HEART). Saf. Reliab. 2015, 35, 26-76. [CrossRef]

57. Bogna, F.; Dell, G.; Raineri, A. Incorporating internal context into the design of occupational health and safety research and intervention programmes in SMEs. Small Enterp. Res. 2018, 25, 168-182. [CrossRef]

58. Gobo, G. Sampling, representativeness and generalizability. In Qualitative Health Research; Seale, C., Gobo, G., Gubrium, J.F., Silverman, D., Eds.; Sage: Thousand Oaks, CA, USA, 2004; pp. 435-455.

59. Galvin, R. How many interviews are enough? Do qualitative interviews in building energy consumption research produce reliable knowledge? J. Build. Eng. 2015, 1, 2-12. [CrossRef]

60. UNI (Italian Committee for Standardization). UNI 11464: 2012—Safety of Machinery—Truck Mixers-Safety Requirement. Available online: https://infostore.saiglobal.com/en-gb/standards/uni-11464-2012-1095365_ SAIG_UNI_UNI_2548821/ (accessed on 3 January 2019).

61. Pinto, A.; Nunes, I.L.; Ribeiro, R.A. Occupational risk assessment in construction industry-Overview and reflection. Saf. Sci. 2011, 49, 616-624. [CrossRef]

62. Bohm, J.; Harris, D. Risk perception and risk-taking behavior of construction site dumper drivers. Int. J. Occup. Saf. Ergon. 2010, 16, 55-67. [CrossRef]

63. INAIL (Italian Workers' Compensation Authority). INFORMO database on serious and fatal accidents. Available online: https:/ / appsricercascientifica.inail.it/getinf_u/getinf.asp? $\mathrm{a}=\& \mathrm{i}=0 \& \mathrm{t}=2 \& \mathrm{~W}=\mathrm{s} \& \mathrm{n}$ (accessed on 3 January 2019). 
64. International Organization for Standardization (ISO). Safety of Machinery—Risk Assessment_Part 2: Practical Guidance and Examples of Methods; ISO/TR 14121-2:2012; International Organization for Standardization: Geneva, Switzerland, 2012.

65. Guarascio, M.; Lombardi, M.; Rossi, G.; Sciarra, G. Risk analysis and acceptability criteria. WIT Trans. Built Environ. 2007, 94, 131-138. [CrossRef]

66. Rowlinson, S.; Jia, Y.A. Construction accident causality: An institutional analysis of heat illness incidents on site. Saf. Sci. 2015, 78, 179-189. [CrossRef]

67. Righi, A.W.; Saurin, T.A.; Wachs, P. A systematic literature review of resilience engineering: Research areas and a research agenda proposal. Reliab. Eng. Syst. Saf. 2015, 141, 142-152. [CrossRef]

68. Patriarca, R.; Di Gravio, G.; Costantino, F.; Falegnami, A.; Bilotta, F. An Analytic Framework to Assess Organizational Resilience. Saf. Health Work 2018, 9, 265-276. [CrossRef]

69. Banks, T.; Freeman, J.; Davey, J. An Engineering or Behavioural Approach? A Study into Employees' Perceptions Regarding the Effectiveness of Occupational Road Safety Initiatives. Safety 2016, 2, 7. [CrossRef]

70. Lingard, H. Occupational health and safety in the construction industry. Constr. Manag. Econ. 2013, 31, 505-514. [CrossRef]

71. Horberry, T.; Burgess-Limerick, R.; Cooke, T.; Steiner, L. Improving Mining Equipment Safety Through Human-Centered Design. Ergon Des. 2016, 24, 29-34. [CrossRef]

72. Man, S.S.; Chan, A.H.; Wong, H.M. Risk-taking behaviors of Hong Kong construction workers-A thematic study. Saf. Sci. 2017, 98, 25-36. [CrossRef]

73. Gunduz, M.; Laitinen, H. A 10-step safety management framework for construction small and medium-sized enterprises. Int. J. Occup. Saf. Ergon. 2017, 23, 353-359. [CrossRef]

74. Fargnoli, M.; De Minicis, M.; Di Gravio, G. Knowledge Management integration in Occupational Health and Safety systems in the construction industry. Int. J. Prod. Dev. 2011, 14, 165-185. [CrossRef]

75. Li, W.; Cao, Q.; He, M.; Sun, Y. Industrial non-routine operation process risk assessment using job safety analysis (JSA) and a revised Petri net. Process. Saf. Environ. Prot. 2018, 117, 533-538. [CrossRef]

76. Voss, C.; Tsikriktsis, N.; Frohlich, M. Case research in operations management. Int. J. Oper. Prod. Manag. 2002, 22, 195-219. [CrossRef]

77. Yin, R.K. Case Study Research: Design and Methods, 4th ed.; Sage: Thousand Oaks, CA, USA, 2008; ISBN 1412960991.

78. Hughes, C.M.; Baber, C.; Bienkiewicz, M.; Worthington, A.; Hazell, A.; Hermsdörfer, J. The application of SHERPA (Systematic Human Error Reduction and Prediction Approach) in the development of compensatory cognitive rehabilitation strategies for stroke patients with left and right brain damage. Ergonomics 2015, 58, 75-95. [CrossRef]

79. European Commission. Guidance on Risk Assessment at Work; Office for Official Publications of the European Communities: Luxembourg, 1996; ISBN 92-827-4278-4.

80. Guarascio, M.; Lombardi, M.; Massi, F. Risk Analysis in handling and storage of petroleum products. Am. J. Appl. Sci. 2013, 10, 965-978. [CrossRef]

81. Park, K.S.; in Lee, J. A new method for estimating human error probabilities: AHP-SLIM. Reliab. Eng. Syst. Saf. 2008, 93, 578-587. [CrossRef]

82. Ghasemi, M.; Nasleseraji, J.; Hoseinabadi, S.; Zare, M. Application of SHERPA to Identify and Prevent Human Errors in Control Units of Petrochemical Industry. Int. J. Occup. Health Saf. 2013, 19, $203-209$. [CrossRef]

83. Mearns, K.; Kirwan, B.; Reader, T.W.; Jackson, J.; Kennedy, R.; Gordon, R. Development of a methodology for understanding and enhancing safety culture in Air Traffic Management. Saf. Sci. 2013, 53, 123-133. [CrossRef]

(C) 2019 by the authors. Licensee MDPI, Basel, Switzerland. This article is an open access article distributed under the terms and conditions of the Creative Commons Attribution (CC BY) license (http:/ / creativecommons.org/licenses/by/4.0/). 